\title{
Teaching Electromagnetism with the Inverted Classroom Approach: Student Perceptions and Lessons Learned
}

\section{Dr. Micah Stickel, University of Toronto}

Dr. Micah Stickel (ECE) is Chair, First Year, in the Faculty of Applied Science \& Engineering. He is also a Senior Lecturer in The Edward S. Rogers Sr. Department of Electrical \& Computer Engineering. Dr. Stickel first came to the Faculty when he started as an undergraduate in 1993. Since that time, he has completed his BASc (1997), MASc (1999), and a PhD (2006) - all with a focus on electromagnetics and the development of novel devices for high-frequency wireless systems. He has a great interest in engineering education and the use of technology to advance the student learning experience. He has been honoured with three departmental teaching awards and was selected as a New Faculty Fellow at the 2008 Frontiers in Education Conference. In 2012, he was awarded the Early Career Teaching Award by the Faculty of Applied Science \& Engineering. 
Teaching Electromagnetism with the Inverted Classroom Approach: Student Perceptions and Lessons Learned 


\section{Introduction}

For a number of years now, engineering instructors throughout the world have begun to experiment with the notion of a "flipped" or "inverted" classroom. This teaching approach encourages students to gain the required base knowledge of a concept prior to class through short "mini-lecture" videos or other preparatory exercises. The great potential for this approach is that it provides instructors with the opportunity to reimagine and redesign the in-class experience to create a more active learning environment.

Recently, this approach was applied to the teaching of an electric and magnetic fields course as part of the second-year electrical and computer engineering curriculum at the University of Toronto, which is a large research-intensive public engineering school. The teaching approach consisted of (a) pre-class lesson videos with embedded viewing quizzes (average length of 25 minutes), and (b) in-class active learning opportunities, including conceptual questions and peer instruction facilitated through a classroom-response system, group work exercises, and opportunities for individual work and consideration of the material at hand.

This work is part of a two-year study in which the course was taught using a traditional instructor-centered approach in year one (2012) and then was taught using the inverted classroom approach in the year two (2013). The author was the same course instructor in both years, and approximately 330 students took the course each year. The study used a mixedmethods design which, in part, included pre/post conceptual assessments, an end-of-course survey, and focus groups sessions. The purpose of this paper is to present the details of how this approach was applied to teach this fundamental course on electromagnetism, summarize the students' perceptions of this new teaching method, and provide some key lessons learned related to this emerging teaching approach.

\section{Background}

The foundation of the inverted classroom is based upon the essential concept that students learn more effectively if they become actively engaged with the material. This is now a welldeveloped tenet of good undergraduate education, which has been demonstrated through numerous studies over the past 50 years ${ }^{1,2}$. It is also well understood that the traditional 50 minute one-way lecturing format is a poor method of teaching due to students' finite attention capabilities $^{3}$. This new approach provides students with the necessary introduction to the course material through shorter 15 to 30 minute videos, and gives them the opportunity to learn the material more deeply through supervised active exercises.

Another advantage of this new teaching method is that it creates a more inclusive learning environment, one which reaches students of different learning styles and diverse cultural backgrounds. Through the availability of the introductory "lesson" videos and the follow-up "lecture" videos, students for whom English is not their first language can watch the videos at their own pace and review them as needed. In addition, the variety of learning experiences which can now be used in the face-to-face time along with the different types of supporting features, allows for a wider array of learning domains to be reached. Indeed, adapting one's teaching approach to meet the needs of a wide range of learning styles leads to a better quality educational experience for all students ${ }^{4}$. 
Over the past 13 years, there has been a growing body of literature relating to the inverted classroom teaching approach. However, as a recent review paper has noted ${ }^{5}$, much of this research focuses primarily on student and instructor perceptions rather than measuring specific learning outcomes. Some more current papers have reported that the use of the inverted classroom approach has little effect on the overall performance of students on common exams, as compared to a traditionally taught cohort ${ }^{6,7}$. Yet another study found a small (but significant) negative effect of the inverted classroom technique on student performance on a standard final exam ${ }^{8}$. What is clear from this research is the need to ensure that students engage properly with the new technique in order to promote a successful learning experience.

\section{Inverted Classroom Approach for Teaching Engineering Electromagnetics}

\section{Instructional Overview}

The study associated with this paper was focused around the teaching of a core second-year course on electric and magnetic fields as part of a standard electrical and computer engineering program at a major research-intensive university. This course takes an engineering approach to the material, but is based upon rigorous vector calculus analysis. The major topics covered within the course for both years were:

1) Electrostatic Source-Field Relationships: Coulomb's law, Gauss's law, and the relationship to electric potential,

2) Electric Properties of Materials: Resistance, Joule's law, dielectrics and polarization, and electric boundary conditions,

3) Applications of Electric Fields: Capacitance and electrostatic potential energy,

4) Design using Electrostatic Fields: Poisson's and Laplace's equations and onedimensional boundary-value problems,

5) Magnetostatic Source-Field Relationships: Biot-Savart law, Ampère's law, magnetic vector potential,

6) Magnetic Properties of Materials: Magnetization, magnetic materials and hysteresis, and magnetic boundary conditions,

7) Applications of Magnetic Fields: Inductance, magnetic energy, magnetic circuits, magnetic forces and DC motors and generators,

8) Time-Varying Fields: Faraday's law, Lenz's law, transformer and motional electromotive forces, AC generators, and displacement current.

The "traditional" style of teaching the course in 2012 did not follow the classic lecturing approach, as a number of technological and active learning components were used. However, this approach was still primarily instructor-led, with the instructor lecturing for much of the class time, and students focused on note-taking. The specifics of this approach included:

- Using the in-class times as the primary opportunity to introduce students to the core concepts within the course and instructor-led demonstrations of both problem-solving examples and simple experiments.

- The tablet PC was used within the class instead of a chalkboard, and students were provided with outlines of the lectures prior to class.

- No fully annotated notes were ever provided to the students. 
- No videos of the lectures were ever made available.

- On average one or two classroom response system (iClicker) questions were used in the lectures (a 3\% bonus mark for the course encouraged participation in these questions).

- No online question and answer discussion forum was used or supported for the course.

The "inverted" style of teaching the course in 2013 involved:

- Students watching a pre-class "lesson" video (average length of 25 minutes), which included pop-up "test yourself" quizzes at appropriate locations (usually two quizzes per video).

- The in-class time was then used for more active learning exercises which included classroom response system conceptual questions with opportunities for peer instruction, individual and group problem-solving exercises, and discussion and consideration of experimental demonstrations.

- During the exercises the instructor would circulate through the lecture hall with approximately 100 students.

- After a period of time for these exercises the instructor would review or present a solution to the problem in collaboration with the students using a tablet PC.

- The in-class time was also used to discuss additional applications and current areas of related research.

- Approximately one-third to one-half of the class was spent with the instructor speaking at the front, but the presentation was not based on pre-planned notes, but rather resulted from the immediate needs of the students, and addressed the particular challenges that arose during the exercises.

- Students were provided with outlines for both the lesson videos and the in-class experiences.

- No fully annotated notes were ever provided to students.

- Videos of the in-class instructor presentation time were made available to students after the class.

- An online question and answer discussion forum was used and supported for the course 9 .

\section{Inverted Cohort Lesson Video Viewing Habits}

In total, there were 32 lesson videos prepared for the 37 lecture course. Throughout the term, the online service through which the videos were hosted, CoursePeer ${ }^{9}$, tracked the viewing of each video by each student, so it was possible to assess which students watched the majority of the video prior to the appropriate class. Figure 1 summarizes the percentage of students who completed the preparation, and on average 54\% of students watched the lesson before coming to class. It is interesting to note that the three significant dips occurred when students had a significant midterm or quiz in one of their other courses near the day of that class. 
At the end of the term each cohort was administered a survey in the last class. A small percentage of students $(<10 \%)$ completed the survey around that date through an online provider. The overall response rates were: Traditional $n=179$ (59\% response rate), Inverted $n=180(54 \%$ response rate).

As part of this survey students were also asked
Figure 1. Percentage of Class who Viewed the Lesson Video Prior to Class

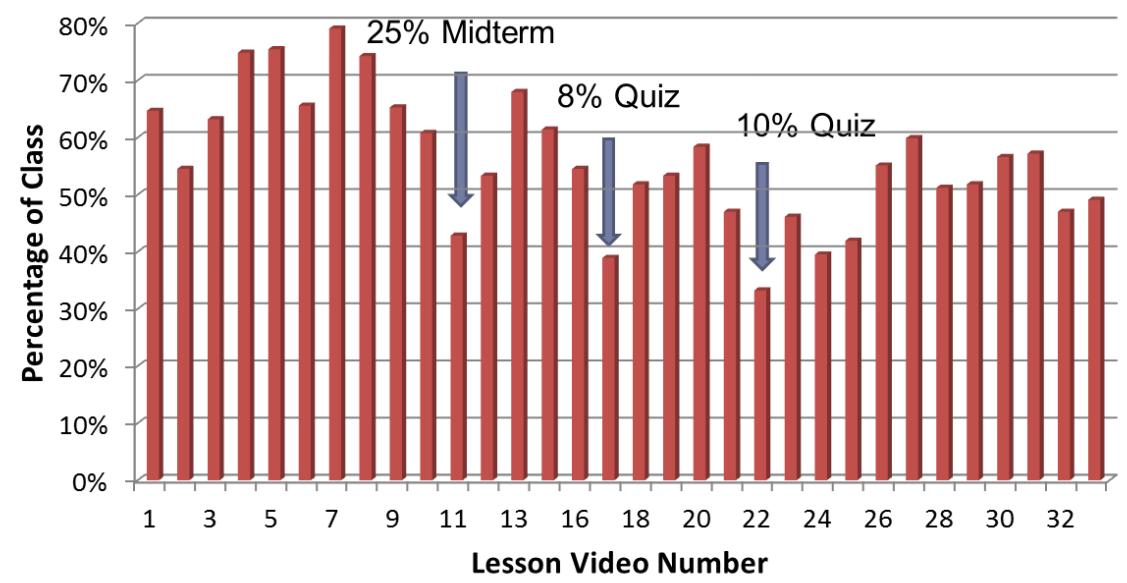

what they typically did during their lesson video viewing and the results are summarized in Figure 2. Of note is the fact that the majority of students did not use the posted lesson outlines, which were designed to provide them with an organized framework for their note taking and included key headings and definitions, complicated figures, and detailed problem statements. There was some concern that since students were accumulating credit towards a 7\% Class Participation grade component by watching the videos beforehand that they would just let the video play in the background of other work. It was reassuring to see that only $9 \%$ reported this type of behaviour.

Figure 2. Student Response to "When I watched the lesson videos, I usually:"

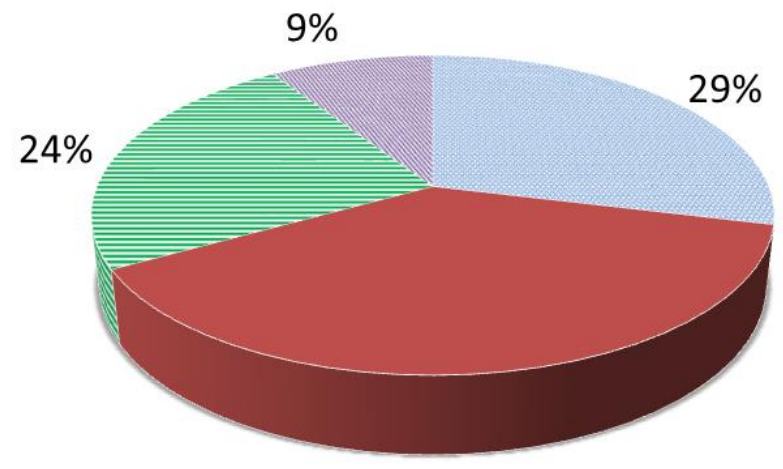

$38 \%$
Took notes using the posted lesson outlines.

- Took my own notes.

$\equiv$ Did not take notes, but I focused on trying to understand the material.

I did not pay much attention to the video as it played.

\section{Lecture Attendance}

In both years, lecture attendance was taken in most of the classes through a sign-in sheet that was passed around during the class. These results were then manually entered and tabulated at the end of each year. As observed for this course over the past many years, each cohort had a similar drop-off profile of attendance with approximately $50 \%$ of students attending the final days of class. The inverted cohort had a slightly higher total attendance percentage than the traditional cohort $(59.4 \%$ compared to $54.6 \%, p<0.05)$. The attendance grouping by percentage of classes attended is summarized in Table 1 . While no statistically significant 
differences were observed in this data, it is interesting to note that $41.4 \%$ of the inverted cohort students attended over $70 \%$ lectures as compared to $35.7 \%$ for the traditional cohort. This was surprising given that the traditional cohort was not offered any videos of the in-class presentation, yet the inverted cohort was provided with these videos.

Figure 3 illustrates the primary reason students gave for why they missed the lectures that they did. It should be noted that roughly $9 \%$ of respondents in both years answered "Other", which is not shown in this figure. The "Other" reasons included sleeping in, subway delays and commuting, and having a test on that day. The major difference in the "Too much work" responses could be due to the fact that one of the other courses in this term modestly reduced their design project requirements from 2012 to 2013. However, this is likely only part of the reason given that the change was not as drastic as the data reflects. The fact that $16 \%$ of the inverted cohort chose "Too early" is likely due to the fact that of the three lecture sections, one section did have a 9 AM class, while for the traditional cohort the earliest class was 10 AM. Finally, a sizable number of students in the inverted cohort (20\%) thought that they were too far behind to make attending the lecture useful. With comments in the following question such as, "Couldn't watch the lesson video, therefore I thought going into the lecture wouldn't be helpful for me since I would not be able to understand it for an hour," it is clear that for some the lesson video requirement had a negative impact at times. Indeed, one of the key pieces of early feedback from the students was asking for the lectures to start with a brief 5 minute overview of the key points from the lesson videos in case they had not seen the video or had watched it a few days prior.

\section{Students' Perceptions \\ Inverted Cohort}

Overall, the inverted cohort responded quite positively to the pre-class lesson videos, as evidenced from the data summarized in Table 2. They found the videos were an effective introduction and that the embedded "test yourself" quizzes spread throughout the videos were helpful. From the open-ended comments, students appreciated having the opportunity to pause, and rewind the video, and the fact that the videos were available for later review prior to the midterm and final exam. It does appear that students found the length of the videos were too long, given that they ranged from 15 minutes to 40 minutes with an average length of 25 minutes.
Table 1. Lecture Attendance Grouping

\begin{tabular}{|lll||}
\hline $\begin{array}{l}\text { Maximum Percentage } \\
\text { of Classes Attended }\end{array}$ & $\begin{array}{l}2012 \\
(\mathrm{n}=336)\end{array}$ & $\begin{array}{l}2013 \\
(\mathrm{n}=334)\end{array}$ \\
\hline $10 \%$ & $9.5 \%$ & $4.8 \%$ \\
$20 \%$ & $5.7 \%$ & $7.2 \%$ \\
$30 \%$ & $7.1 \%$ & $5.7 \%$ \\
$40 \%$ & $8.0 \%$ & $10.5 \%$ \\
$50 \%$ & $9.8 \%$ & $9.0 \%$ \\
$60 \%$ & $11.3 \%$ & $8.4 \%$ \\
$70 \%$ & $12.8 \%$ & $13.2 \%$ \\
$80 \%$ & $12.5 \%$ & $11.1 \%$ \\
$90 \%$ & $15.5 \%$ & $16.5 \%$ \\
$100 \%$ & $7.7 \%$ & $13.8 \%$ \\
\hline
\end{tabular}

Figure 3. Primary Reason for Missing Lectures

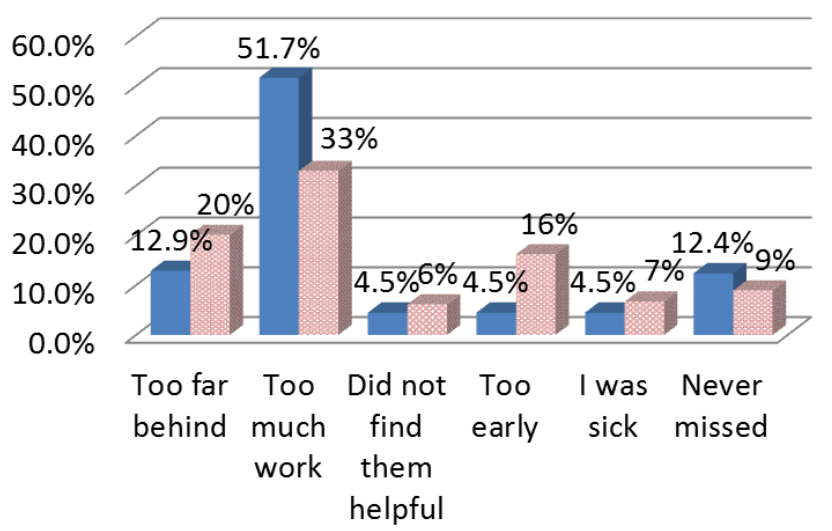


Table 2. Student Response to the Lesson Videos

\begin{tabular}{|c|c|c|c|c|c|}
\hline $\begin{array}{l}\text { Please indicate to what extent you agree or } \\
\text { disagree about the following statements about } \\
\text { lesson videos. }\end{array}$ & Disagree & $\begin{array}{l}\text { Neither } \\
\text { agree or } \\
\text { disagree }\end{array}$ & Agree & $\begin{array}{l}\text { Mean } \\
\text { (Scale } \\
\text { of } 7)\end{array}$ & $\begin{array}{l}\text { Standard } \\
\text { Deviation }\end{array}$ \\
\hline $\begin{array}{l}\text { The lesson videos were an effective introduction } \\
\text { to the main concepts covered in the course }\end{array}$ & $8.3 \%$ & $8.9 \%$ & $82.8 \%$ & 5.62 & 1.39 \\
\hline $\begin{array}{l}\text { The lesson videos effectively prepared me for the } \\
\text { lectures which followed }\end{array}$ & $11.2 \%$ & $7.3 \%$ & $81.6 \%$ & 5.45 & 1.36 \\
\hline The lesson videos were interesting & $20.6 \%$ & $17.2 \%$ & $62.2 \%$ & 4.82 & 1.57 \\
\hline $\begin{array}{l}\text { The quizzes that were embedded in the videos } \\
\text { were very helpful to me in developing my } \\
\text { understanding of the course material. }\end{array}$ & $18.3 \%$ & $16.1 \%$ & $65.6 \%$ & 4.88 & 1.48 \\
\hline The length of the lesson videos was appropriate. & $47.2 \%$ & $13.3 \%$ & $39.4 \%$ & 3.86 & 1.75 \\
\hline
\end{tabular}

Table 3. Student Response to the Inverted Classroom Experience

\begin{tabular}{|c|c|c|c|c|c|}
\hline $\begin{array}{l}\text { In comparing the "inverted classroom } \\
\text { approach" that was used in ECE221 with } \\
\text { courses that you have had which were taught } \\
\text { using the "traditional" lecturing approach, ... }\end{array}$ & Disagree & $\begin{array}{l}\text { Neither } \\
\text { agree or } \\
\text { disagree }\end{array}$ & Agree & $\begin{array}{l}\text { Mean } \\
\text { (Scale } \\
\text { of } 7) \\
\end{array}$ & $\begin{array}{l}\text { Standard } \\
\text { Deviation }\end{array}$ \\
\hline $\begin{array}{l}\text { Overall, the inverted classroom approach } \\
\text { allowed me to make effective use of my time to } \\
\text { develop my understanding of the course } \\
\text { material }\end{array}$ & $35.0 \%$ & $16.7 \%$ & $48.3 \%$ & 4.27 & 1.74 \\
\hline $\begin{array}{l}\text { The inverted classroom approach make the in- } \\
\text { class time more useful in developing my } \\
\text { understanding of the course material. }\end{array}$ & $37.8 \%$ & $10.6 \%$ & $51.7 \%$ & 4.24 & 1.80 \\
\hline $\begin{array}{l}\text { The inverted classroom approach made the in- } \\
\text { class time more enjoyable }\end{array}$ & $25.6 \%$ & $18.3 \%$ & $56.1 \%$ & 4.52 & 1.71 \\
\hline $\begin{array}{l}\text { With the inverted classroom approach I did not } \\
\text { have to "cram", or catch up as much as I } \\
\text { normally would have had to before the term test } \\
\text { and the midterm. }\end{array}$ & $52.2 \%$ & $12.8 \%$ & $35.0 \%$ & 3.60 & 2.02 \\
\hline $\begin{array}{l}\text { I feel that I was given all the support I needed } \\
\text { in this course to learn the material well. }\end{array}$ & $12.2 \%$ & $17.2 \%$ & $70.6 \%$ & 5.21 & 1.53 \\
\hline $\begin{array}{l}\text { I feel that I had the opportunity to get all of my } \\
\text { questions about the material answered (i.e., in } \\
\text { class, with the instructor, on CoursePeer, etc.) }\end{array}$ & $10.1 \%$ & $16.8 \%$ & $73.2 \%$ & 5.21 & 1.34 \\
\hline $\begin{array}{l}\text { In comparison with the tradition lecturing } \\
\text { approach, I prefer the inverted classroom } \\
\text { approach. }\end{array}$ & $34.6 \%$ & $16.8 \%$ & $48.6 \%$ & 4.15 & 1.95 \\
\hline $\begin{array}{l}\text { Overall, the inverted classroom approach in this } \\
\text { course has provided me with an effective } \\
\text { learning experience. }\end{array}$ & $25.6 \%$ & $18.9 \%$ & $55.6 \%$ & 4.52 & 1.73 \\
\hline
\end{tabular}


The data summarized in Table 3, relates to the students' overall experience of the inverted classroom. These results clearly show that the students are hesitant to fully embrace this new teaching approach. Only $49 \%$ of students said they would prefer this approach over the traditional lecturing method, and the majority of students (52\%) reported that they did not find that the small investments of time into the learning the course material prior to class resulted in less "cramming" for a midterm or final exam.

It is also concerning that about $35 \%$ of the students disagreed that this approach allowed them to make effective use of their time both in class and outside of class. Indeed, one of the primary purposes of this approach is to ensure that students invest small amounts of meaningful time into the course throughout the term and prior to each class. In this way, they can develop their understanding through appropriately scaffolded exercises that follow up on this foundational experience. While efforts were made to strategically link the lessons and lectures, clearly this is an area that needs further improvement for future offerings of this course. On the other hand, it is interesting to note that more than $70 \%$ of students stated that they were given all the help they needed to learn the course material and had the opportunity to have all their questions answered.

\section{Cohort Comparisons}

For the most part there were few significant differences between how the traditional and inverted cohorts responded to the various aspects of the course through the end-of-course survey. Those responses that did not exhibit any statistically significant differences related to the:

1) Helpfulness of the tutorials, which were taught with the same group-work format in both years (Trad. mean (on a scale of 7) $=3.83$, Inv. mean $=3.98, p=0.379$ ),

2) Course workload, both cohorts rated the work required for the course in similar ways (Trad. mean $=4.73$, Inv. mean $=4.48, p=0.138$ ), which indicated that students did not perceive the video viewing as overly onerous,

3) Overall enjoyment in taking the course, (Trad. mean $=4.74$, Inv. mean $=5.05, p=0.61$ ).

However, students in the traditional cohort did respond more positively to the question, "The lecturing approach that the instructor took was effective in helping me learn the material in the course", as shown in Figure 4. Over $82 \%$ of the traditional cohort agreed with the statement as compared to $71 \%$ of the inverted cohort $($ Trad. mean $=$ 5.43, Inv. mean $=5.11, p=0.27$ ). These results suggest two main things, which both relate to the fact that this was the first experience with the inverted teaching approach for both the
Figure 4. Effectiveness of the Lecturing Approach

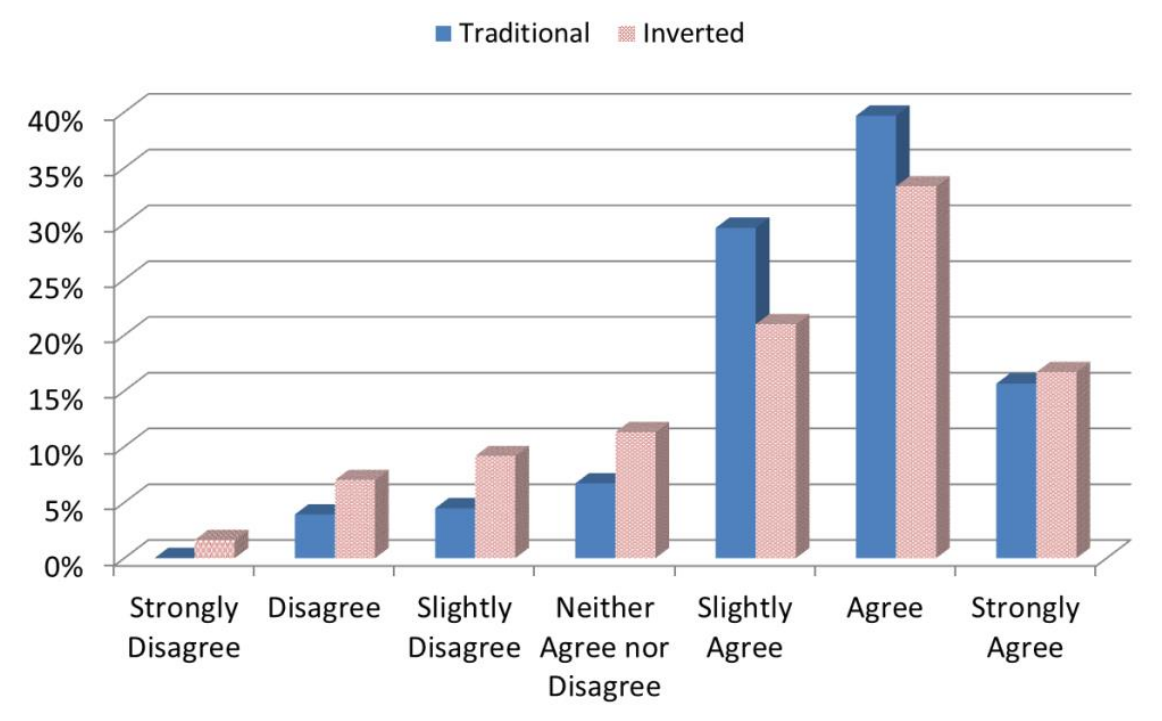


students and the instructor. The in-class exercises need to be improved to provide more interactive and constructive experiences, rather than primarily active exercises, as defined by Menekse, et. $\mathrm{al}^{10}$. As well, the instructor needs to provide more direct facilitation throughout the term to support students in the transition to this new style of learning.

\section{Comparison of Student Learning}

Two measures that were used to assess the students' learning of the course material were:

\section{1) Concept Inventory Pre/Post Quizzes}

Both cohorts were given the same pre/post quizzes in the first and last weeks of the term. The pre-test was the verified Brief Electricity and Magnetism Assessment (BEMA) test ${ }^{11}$ developed by a group of physics educators. Students were given a $1.5 \%$ grade as part of their course mark for just writing the test. The post test included 14 questions from the BEMA pre-test and 14 questions from the Electric and Magnetic Fields concept inventory created by Branislav Notaros ${ }^{12}$. Students were given a $1.5 \%$ bonus mark for the course just for writing the test. A gain score was calculated using the standard Hake formula ${ }^{13}$, based on the common 14 questions of both tests.

\section{2) Overall Course Academic Performance}

The overall average for each student for the course was also considered. The overall marking scheme was kept quite similar and the two cohorts had the same tutorial and computer lab experiences. As well, the course had three major assessments including a term test (10\% - 2012, and 8\% - 2013), a midterm (20\%), and a final exam (40\%). It should be noted that while the test, midterm, and exam covered all the same material and included similar types of questions, the questions were not the same for both years due to the fact that these were available to the students from previous years.

\section{Concept Inventory Pre/Post Quizzes}

The comparison of the performances of the two cohorts on the pre/post quizzes is summarized in Table 4. There was no statistically significant differences found in the performances of these two quizzes or the overall gain. The similar pre-test score is one indication of the similarity between the incoming nature of the two cohorts. This was also verified by analyzing the prior academic performance of the two groups, see Table 5 below.

Table 4. Comparison of Pre/Post Quiz Performances

\begin{tabular}{|c|c|c|c|c|c|}
\hline \multicolumn{2}{|l|}{ Concept Inventory Quiz } & $n$ & Mean & $\begin{array}{c}\text { Std. } \\
\text { Deviation } \\
\end{array}$ & $\begin{array}{l}\text { Sig. of Mean } \\
\text { Diff. }(p) \\
\end{array}$ \\
\hline \multirow{2}{*}{$\begin{array}{l}\text { Pre-Quiz } \\
\text { (31 questions) }\end{array}$} & Traditional Cohort (2012) & 308 & 46.0 & 15.4 & \multirow{2}{*}{0.89} \\
\hline & Inverted Cohort (2013) & 332 & 46.1 & 15.2 & \\
\hline \multirow{2}{*}{$\begin{array}{l}\text { Post-Quiz } \\
\text { ( } 28 \text { questions, } 14 \text { of which } \\
\text { were the same as the pre-quiz) }\end{array}$} & Traditional Cohort (2012) & 289 & 51.3 & 19.1 & \multirow{2}{*}{0.49} \\
\hline & Inverted Cohort (2013) & 318 & 50.2 & 18.4 & \\
\hline \multirow{2}{*}{$\begin{array}{l}\text { Gain based on common } 14 \\
\text { questions of pre/post quizzes }\end{array}$} & Traditional Cohort (2012) & 280 & 17.9 & 48.7 & \multirow{2}{*}{0.23} \\
\hline & Inverted Cohort (2013) & 303 & 13.4 & 41.6 & \\
\hline
\end{tabular}


One of the confounding factors in the writing of the post quiz was that students were only given a $1.5 \%$ credit for simply writing the quiz. No marks were given to the performance on the quiz and students were told they did not need to "study for the quiz". However, the traditional cohort had the course final exam 4 days after the post concept quiz, so they had already started to review the course material. Whereas for the inverted cohort, the post concept quiz was written 11 days before the course final exam, so students came in without any prior review or preparation. Given this, it is encouraging that the inverted cohort performed as well as they did on the post test. For this type of measure to be of significant use, the two post quizzes should be incorporated into the final exam.

\section{Overall Course Academic Performance}

The prior academic performance and overall course averages for the two cohorts are summarized in Table 5. The prior academic performance was based on the average of each student's first 15 courses in the Electrical and Computer Engineering program. This represents the first three terms of study prior to when the course which is the focus of this paper is taken. As the pre-test data also indicated, the two cohorts entered the course with a similar academic foundation.

In addition, the distributions of the grades are shown in Figure 5, relative to the percentage of students enrolled in the course. While the course assessments were non-standard, it is interesting to observe the difference in the overall distributions of the course grades. This difference indicates that the inverted cohort resulted in more students achieving grades of $\mathrm{A}$ and $\mathrm{A}+$.

Table 5. Comparison of Prior Academic Performance and Final Course Averages

\begin{tabular}{|l|c|c|c|c|c||}
\hline \multirow{2}{*}{} & \multirow{2}{*}{} & \multicolumn{2}{|c|}{$\begin{array}{c}\text { Prior Academic } \\
\text { Performance* }\end{array}$} & \multicolumn{2}{c||}{ Final Course Mark } \\
\cline { 3 - 6 } & $n$ & Mean & Std. Dev. & Mean & Std. Dev. \\
\hline Traditional Cohort (2012) & 299 & 73.2 & 9.3 & 70.4 & 13.2 \\
\hline Inverted Cohort (2013) & 329 & 73.7 & 9.3 & 73.4 & 13.1 \\
\hline \multicolumn{3}{|c|}{0.5} & \multicolumn{2}{|c|}{$3.0^{+}$} \\
\hline
\end{tabular}

$*$ Average of first 15 courses in the Electrical and Computer Engineering program $+p<0.01$

\section{Figure 5. Comparisons of Final Mark Distributions}

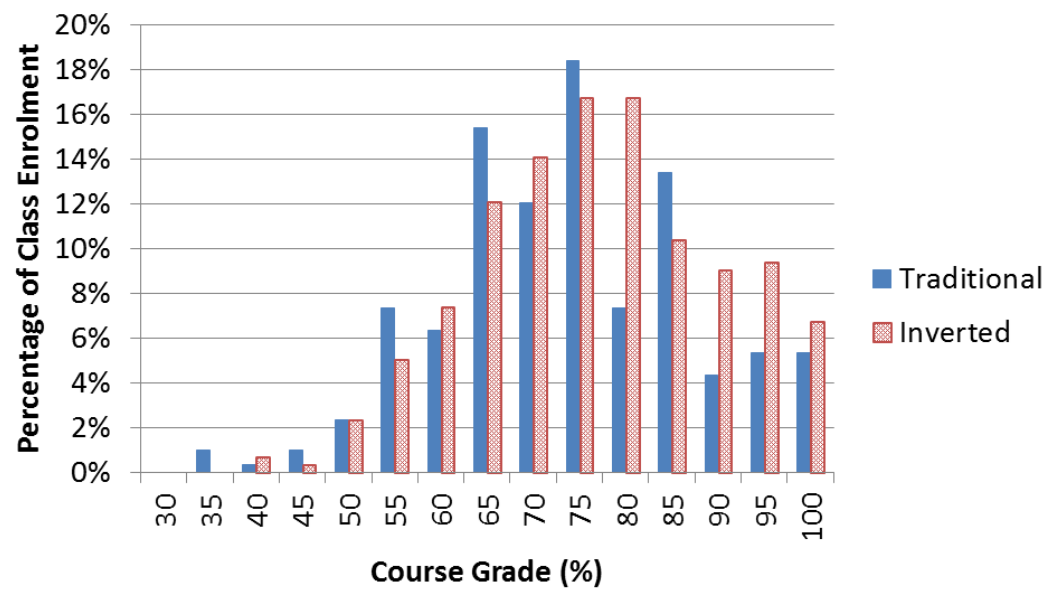




\section{Lessons Learned}

\section{Student Engagement}

In order for the inverted classroom approach to improve students' learning, the students must take more ownership over their own learning process. As instructors move away from the stage, they need to become more adept facilitators of the holistic learning experience. This includes enabling the necessary support and motivation for students so that they see value in the new learning method.

As the results in this paper indicate there was not an overwhelmingly positive student response to the new approach, so further work is needed to properly motivate the reasons and benefits of this teaching style. In future offerings of this course in an inverted form, the instructor will:

1) Ensure that "learning how to learn" is an integral part of the entire course, and discuss and introduce fundamental concepts of how people learn effectively throughout the course. In both the traditional and inverted cohorts an exercise was run towards the end of the term which asked students to assess their learning style, critique this learning style assessment, and consider what teaching and studying techniques best help them learn. In future offerings of this inverted class, this will be integrated into the course earlier on in the term.

2) Include statistical results from the previous offering to demonstrate the usefulness of the approach.

3) Provide a more seamless integration of the pre-class lesson videos and the in-class learning experiences by providing quick, simple review assessments and exercises at the beginning of the class.

4) Gather feedback from the students throughout the term, to ensure that small improvements are made as needed and to enable the students to take more ownership in the course design.

\section{Lesson Video Creation and Hosting}

To create the pre-class lesson videos, the instructor used the first 30 to 40 minutes of their previous 50 minute lecture content, which typically included a short discussion of motivation, review, or introduction, a derivation of the core idea or law and/or a definition of the key terms or concepts, and one or two problem-solving examples. In this way the creation of the videos was not very difficult and the videos were simple voice over annotated PowerPoint slides created using Camtasia Studio ${ }^{14}$. The videos were created in small sections of about 10 to 15 minutes (in order to ensure recorded content was saved), but a running take was done which included mistakes and redone sections. While this made the video creation easy, significant time was then needed to edit the raw video down to the final version (i.e., remove the sections with mistakes). This took approximately a half-hour to hour of editing for a 30 minute final video.

In order to achieve the embedded pop-up quizzes and the necessary level of individual student video analytics CoursePeer was used. This degree of video viewing analytics was extremely useful throughout the term as was the quality of hosting that CoursePeer provided. However, this could also be integrated into an existing course management system with the use of YouTube hosted videos and shorter posted video segments with follow up "test yourself" quizzes or review exercises. 
Overall, the implementation of this approach did take significant time since every lecture was inverted. In addition to the video and embedded quiz creation and set up in the online hosting service, quite a bit of time was needed to create engaging and appropriate in-class exercises. It is certainly recommended to have a significant portion of this work done prior to the start of the term. Alternatively, perhaps a better way to experiment with this new approach is to decide on a handful of topics or lectures to invert and build up over time a complete set of materials if appropriate.

\section{Increased Opportunities for Discussion of Current Applications}

One of the benefits of this technique is that the instructor has some additional flexibility of how to use the in-class time. It is important that the majority of this time be used to reinforce the development of the students' understanding. However, in this course offering the instructor was able to introduce and discuss significantly more engineering applications and areas of current research. As well, the instructor was able to cover more core material with the inverted cohort than was presented in the traditional class. Indeed, the inverted cohort was exposed to a detailed introduction of transmission-line theory, which provided an excellent end to the course.

\section{Conclusions}

This paper has provided an overview of how the inverted classroom approach has been used to teach a course on electric and magnetic fields within an engineering faculty. Overall, students were receptive to the new learning method, however, on average only $54 \%$ of the class watched the required lesson video prior to the associated class. In addition, only $56 \%$ of students agreed that "inverted classroom approach in this course has provided me with an effective learning experience," and only 49\% said they "preferred" the inverted approach relative to the traditional approach. These results demonstrate that instructors should proceed cautiously and ensure that the inverted approach serves a clear and definable purpose for the particular material or course being taught. Since this model of teaching requires a significant shift in the both the teaching and learning approach, it is likely that it will become of greater benefit to certain courses as both the instructor and students become more familiar with its advantages and disadvantages.

It should be noted that students found the lesson videos to be quite useful and appreciated the opportunity to have a well-designed introduction to the core material available for later review. As well, the students in the inverted cohort did not view this approach as significantly more work than their other courses and they "enjoyed" the course as much as the traditionally-taught cohort.

In terms of the students' academic performance in the course, no statistically significant differences were found in the quiz scores and overall gain scores associated with the pre/post series of standardized concept inventory quizzes for the two cohorts. However, within the overall final mark distribution between the two cohorts, it does appear that the inverted classroom resulted in more students in the A and A+ category. These results are tempered by the fact that the major assessments which the final mark is based on had different questions for the two cohorts. Additional learning outcome measures associated with this project support the notion that the inverted classroom cohort performed as well or better than the traditional cohort, as discussed in greater detail in a companion paper $^{15}$. 
The strong theoretical foundation upon which the inverted classroom approach rests indicates that it has great potential to improve the students' learning experience. The initial results presented in this paper are positive, but it is clear that more work needs to be done to support the students' transition to this new method of learning. Many of them are used to the passive instructor-centered traditional approach, and in this new method they are being asked to take a greater leadership role in their learning experience. Ultimately, this promises to result in more significant learning but additional effort is needed to refine this teaching technique such that students become willing and active partners in the experience.

\section{Acknowledgements}

The author would like to express his sincere appreciation for the expertise and kind support of Qin Liu and Siddarth Hari over the entire course of this study. As well, he is very grateful to the Higher Education Quality Council of Ontario (HEQCO) for their financial support and mentorship throughout this project.

\section{Bibliography}

1. McKeachie, W.J., Pintrich, P.R., Lin, Y-G., Smith, D.A.F., and Sharma, R.. Teaching and learning in the college classroom: A review of the research literature ( $2^{\text {nd }}$ ed.). Ann Arbor: NCRIPTAL, University of Michigan, 1990.

2. Chickering, A. W., and Gamson, Z. F., "Appendix A: Seven principles for good practice in undergraduate education," New Directions for Teaching and Learning, Vol. 1991, No. 47, 1991, pp. 63-69.

3. Bligh, D.A., What's the use of lectures?. San Francisco, CA, Jossey-Bass, 2000.

4. Felder, R.M., "Reaching the second tier: Learning and teaching styles in college science education," Journal of College Science Teaching, Vol. 23, No. 5, 1993, pp. 286-290.

5. Bishop, J. L., and Verleger, M. A., "The Flipped Classroom: A Survey of the Research," Proceedings 2013 ASEE Annual Conference \& Exposition, Atlanta, GA, June 2013.

6. Morin, B., Kecskemety, K. M., Harper, K. A., and Clingan, P. A., "The Inverted Classroom in a First-Year Engineering Course," Proceedings 2013 ASEE Annual Conference \& Exposition, Atlanta, GA, June 2013.

7. Love, B., Hodge, A., Grandgenett, N., and Swift, A. W., "Student learning and perceptions in a flipped linear algebra course," Int. J. of Mathematical Education in Science and Technology, 2013.

8. McClelland, C. J., "Flipping a Large-enrollment Fluid Mechanics Course - Is it Effective?," Proceedings 2013 ASEE Annual Conference \& Exposition, Atlanta, GA, June 2013.

9. Coursepeer (http://www.coursepeer.com/) was the system used to implement the inverted classroom, which included the hosting of videos, running embedded quizzes, posting of outlines, and an online question and answer discussion forum.

10. Mehekse, M., G. S. Stump, S. Krause, and M. T. H. Chi, "Differentiated Overt Learning Activities for Effective Instruction in Engineering Classrooms," J. Eng. Education, Vol. 102, No. 3, pgs. 346 - 374, July 2013. 
11. Ding, L., R. Chabay, B. Sherwood, and R. Beichner, "Evaluating an electricity and magnetism assessment tool: Brief electricity and magnetism assessment," in Phys. Rev. Special Topics - Phys. Ed. Research, 2 (010105), pgs. $1-7,2006$.

12. Notaros, B. M., "Concept Inventory Assessment Instruments for Electromagnetic Education," in Proc., IEEE Antennas and Propagation Society Int. Symp., San Antonio, Texas, 2002.

13. Hake, R., "Interactive-engagement versus traditional methods: A six-thousand-student survey of mechanics test data for introductory physics courses," Amer. J. of Phys., Vol. 66, No. 64, 1998.

14. Camtasia Studio 8.0, TechSmith, available at http://www.techsmith.com/camtasia.html, accessed January 3, 2014.

15. Stickel, M., Liu, Q., and Hari, S., "The Effect of the Inverted Classroom Teaching Approach on Student/Faculty Interaction and Students' Self-Efficacy,", Proceedings 2014 ASEE Annual Conference \& Exposition, Indianapolis, IN, June 2014. 